\title{
WALTER
}

BENJAMIN: DE LA

REPRODUCCIÓN

TÉCNICA AL

ESPECTÁCULO

Eduardo Subirats*

La obra de Walter Benjamin ha sido asociada en los últimos años con una idiosincrática teoría estética y una historia idiosincrática de las formas de la sensibilidad, con el estilo personal del ensayista dotado de una delicada expresividad poética, y con una original teoría de la obra de arte moderna bajo el aspecto del aura. A esta predominancia de lo estético sobre lo político y lo sociológico, y aun sobre lo epistemológico, la reciente interpretación de la obra benjaminiana ha añadido los temas blandos adecuados a una década intelectualmente débil: los momentos de la nostalgia y la melancolía, y una cierta identificación vaga con aquellos aspectos formales de un pensamiento negativo, como lo fragmentario y ensayístico, la mirada minuciosa de orfebre y lo aforístico, aspectos de la obra de Benjamin y de su talento literario a los que se había sustantivado como formalistas principios estilísticos de una visión intelectual acentuadamente estetizante. Bejamin ha resultado ser el melancólico intimista, el bohemio, el amante visual, el perezoso soñador, el escéptico, el geógrafo de lo imaginario, el nostálgico... y la lista de dulces apodos se diría que no tiene fin. Y allí donde se tocaba el tema de lo que mal podría llamarse la teoría estética de Benjamin, esta perspectiva blanda rezaba aproximadamente una

${ }^{*}$ Ensayista Español. 


\section{Eduardo Subirats}

letanía del aura. Benjamin habría adivinado que el arte moderno había perdido los maravillosos perfumes teológicos que confirieron otrora a los cuadros o a los muebles viejos la dimensión metafísicamente profunda de una atmosférica santidad. A este propósito se citaba la definición misteriosa de aura a modo de contraseña filosófica para entendidos: la manifestación irrepetible de una lejanía por cercana que pueda estar. El aura se celebraba como un paraíso perdido del arte histórico. La crítica benjaminiana de la modernidad apelaba así retroactivamente a inciertos anhelos aristocráticos y teológicos. Había que salir al encuentro del tesoro abscóndito. La profética revolución hacia atrás. Y el pequeño secreto para pocos.

Las tesis de Benjamin sobre La obra de arte en la época de su reproductibilidad técnica no abordan, como problema nuclear, la constelación estética de la pérdida del aura subsiguiente a la reproducción técnica de la obra de arte en lo que considera los géneros artísticos modernos por excelencia: la fotografía y el cine. De manera explícita, Benjamin formula en el "Prólogo" a este ensayo de estética que su objeto es el estudio de la "transformación de la superestructura". ${ }^{1}$ En la civilización industrial avanzada, palabras que señalan por sí mismas una problemática bastante más amplia. La cuestión pertenece más bien a la teoría crítica de la sociedad que a una teoría estética en un sentido estricto de la palabra. Sin embargo, Benjamin descubre que esta adaptación de la "superestructura" al desarrollo tecno-económico de las sociedades capitalistas está intimamente ligada a la revolucionaria transformación ontológica de la obra de arte moderna, consecuente a su incorporación de los procesos de reproducción técnica. La reproducción técnica no es entendida en este contexto como un procedimiento añadido y exterior a la obra de arte, sino como el principio constitutivo de la nueva naturaleza de la obra de arte moderna, y como la condición objetiva de su renovada función

${ }^{1}$ Walter Benjamin, Discursos interrumpidos I, Madrid, 1973, p. 18. 


\section{DE LA REPRODUCCIÓN TÉCNICA AL ESPECTÁCULO}

social, o sea, de su "aspiración a las masas". ${ }^{2}$ Esta última no se desprende, de acuerdo con Benjamin, de un proceso ideológico, como tampoco de una intención política. Es más bien el resultado de la transformación cualitativa de la naturaleza de la obra de arte, subsiguiente a su reproducción y extensión técnicas.

La originalidad y radicalidad del planteamiento teórico benjaminiano reside, en primer lugar, en considerar la ruptura revolucionaria y la transformación estructural de la obra de arte moderna no desde una perspectiva crítico-ideológica, sino a partir de los cambios de la percepción, o más bien de las nuevas formas de la construcción social de la realidad inmediatamente derivadas de las técnicas de reproducción. Es esta la perspectiva teórica que distingue nítidamente la interpretación benjaminiana de las estéticas marxistas de este siglo, e incluso de la crítica de la función afirmativa de la cultura desarrollada por Marcuse tan sólo un año después de la publicación de aquel ensayo de Benjamin.

El modelo analítico de la transformación de la obra de arte en la era de la técnica lo ofrece el cine. Sus características formales, el predominio. del "aparato" sobre la persona, y del proceso "inconsciente" de montage sobre el proceso de la experiencia consciente, la prevalencia del valor expositivo sobre la contemplación, y la construcción de lo real como una segunda naturaleza, no solamente plantean para Benjamin la necesidad de una nueva y revolucionaria aproximación estética al nuevo arte, sino también la reformulación de la teoría crítica de la sociedad. Una crítica social que se cristaliza, por lo pronto, en el análisis benjaminiano del nacional-socialismo. Pero que traspone el análisis del nacional-socialismo precisamente de un plano crítico-ideológico al de la concepción de la política como obra de arte, de la producción industrial de la conciencia, y de lo que hoy puede definirse como la construcción mediática de la realidad. El concepto bajo el que Benjamin resume esta perspectiva crítica es la "estetización de la política".

${ }^{2}$ Ibid., p. 45. 
Eduardo Subirats

El sentido mesiánico, socialmente emancipador del análisis de la obra de arte moderna bajo el aspecto de su última consecuencia humana, o sea, la "estetización de la política", se cristaliza a lo largo de las tesis sobre $L a$ obra de arte en la época de su reproductibilidad técnica en una crítica de la tecnología convertida en hybris: la crítica a lo que Benjamin llama la "insurrección de la técnica". ${ }^{3}$ En la recensión Teorías del fascismo alemán, se perfila de nuevo el motivo recurrente de esta crítica: la guerra como consecuencia de una tecnología y un progreso tecnológicos no dominados por el ser humano. Este es también uno de los motivos más relevantes de las tesis Sobre el concepto de historia. La otra dimensión bajo la que se articula esta voluntad mesiánica es la experiencia. Ella aparece ambiguamente ligada, en las tesis sobre la Reproductibilidad ténica, con la problemática del aura, y es formulada en su figura políticamente reflexiva en la declaración final de este ensayo: "el comunismo responde (a la estetización nacional-socialista de la política) con la politización del arte", es decir, la apelación a una dimensión reflexiva de la experiencia estética.

Sin embargo, el tema de la experiencia se plantea también desde un punto de vista epistemológico y metafísico en una serie de textos, tanto del período juvenil como de la etapa madura de Benjamin. Uno de ellos, en los que la teoría de la experiencia se despliega con todo el rigor de un impetuoso programa juvenil, es el ensayo titulado Sobre el programa de la filosofía venidera.

Kantiano en su concepción fundamental, cercano a la discusión de la escuela neokantiana de comienzos de siglo, en particular de Cohen, Benjamin plantea en este ensayo al menos tres tópicos de interés fundamental: la extensión del concepto kantiano de experiencia más allá de su limitación a las ciencias, la integración del concepto crítico de experiencia del conocimiento al sujeto empírico, o mas bien a la pluralidad social e histórica de sujetos empíricos, y la ampliación de este concepto nuevo

${ }^{3}$ Ibid., p. 57. 


\section{DE LA REPRODUCCIÓN TÉCNICA AL ESPECTÁCULO}

de experiencia al conocimiento religioso. "Este nuevo concepto de la experiencia fundada sobre nuevas condiciones del conocimiento, sería de por sí el lugar lógico y la posibilidad lógica de la metafísica". 4

Lo que Benjamin desarrolla analíticamente en La obra de arte en la época de su reproductibilidad técnica, en el ensayo sobre Baudelaire y en la obra de los Pasajes, en las tesis sobre El narrador, así como en otros artículos, a saber, la reconstrucción de las figuras históricas de la experiencia, se eleva aquí a un programa metafísico de inspiración kantiana: la transformación de la experiencia cognitiva, que el positivismo filosófico orienta en un sentido exclusivamente científico-matemático, a una experiencia teológica y metafísica. Esta nueva estructura de la experiencia la funda Benjamin en una filosofía del lenguaje.

En su artículo Enseñanza de lo semejante, Benjamin recurre a un símil para explicar la relación entre la nueva experiencia y la teoría del lenguaje: la astrología. Esta parte de una percepción de las analogías suprasensibles entre las constelaciones estelares y la existencia humana, para las que, sin embargo, ya el hombre moderno ha perdido todo sentido perceptor. Pero Benjamin añade: "Poseemos, no obstante, un canon que permite echar luz sobre la oscura morada de la semejanza extrasensorial. Y este canon es el lenguaje". 5

La teoría del lenguaje que desarrolla Benjamin puede resumirse con un lacónico enunciado. El lenguaje es mimesis. Benjamin cita a este propósito a Leonhard: "Cada palabra es -y todo el lenguaje es- onomatopéyico". $^{6}$ Eso no significa en modo alguno apelar a una doctrina naturalista de la experiencia mimética en el sentido en que, por ejemplo, la configuró negativamente la moderna pintura abstracta. En el ensayo de Benjamin sobre Calderón y Hebbel se dice con respecto al concepto

${ }_{5}^{4}$ Walter Benjamin, Gesammelte Schriften, Frankfurt a.M., 1974, Bd. 2.1., p. 163.

${ }^{5}$ Ibid., B.d. 2.1., p. 207.

${ }^{6}$ Ibid., Bd. 2.1., p. 207. 


\section{Eduardo Subirats}

de mimesis en la tragedia griega: el objeto de la mimesis no es la "imagen ejemplar" (Vorbild), sino la "imagen ancestral" (Urbild). ${ }^{7}$ Y en el Origen del drama alemán se subraya en el mismo sentido que "en la contemplación filosófica la idea se libera como palabra a partir de lo más interior de la realidad". 8

La teoría del lenguaje de Benjamin arranca de una concepción idealista del acto de nombrar, identificado con el acto adamita de la creación de un mundo, y al mismo tiempo es una teoría del lenguaje como medium de una experiencia mimética de lo real. Como tal la desarrolla Benjamin en su ensayo Sobre el lenguaje en general y sobre el lenguaje de los humanos. En este trabajo la experiencia o la participación mimética se definen en tanto que articulados en el lenguaje como medium de una comunicación universal de los seres espirituales. Ello significa dos cosas fundamentales. La primera es la concepción del lenguaje como inmediato o idéntico con el ser espiritual. O bien, lo que viene a decir lo mismo, el rechazo de la concepción instrumental del lenguaje como simple medio. Hablamos en el lenguaje, no a través de él -subraya Benjamin. El lenguaje no es, en modo alguno, un sistema o aparato de signos exterior al ser humano y a las cosas. Sucede todo lo contrario. La entidad espiritual de lo humano es precisamente "el lenguaje empleado en la creación", según lo ha interpretado R. Blatt. ${ }^{9}$ Es el lenguaje en el que el ser humano ha sido creado con las cosas, y en el que ha sido creado a su vez como creador en el lenguaje como medium de la participación mimética con ellas. En segundo lugar, este carácter medial del lenguaje, o sea esta inmediatez del ser humano como ser espiritual con las palabras, supone una participación mágica con el ser de todas las cosas. Más aún, es idéntico con este ser espiritual de las cosas. La brecha entre el

7 "El mayor monstruo de los celos" von Calderón und "Herodes und Marianne" von Hebbel, en: Walter Benjamin, Ibid. Bd. II.1, p. 249.

${ }^{8}$ Ursprung des deutschen Trauerspiels, en Walter Benjamin, Ibid., Bd. I-1, p. 217.

${ }^{9}$ En la oración original "Sein gesitiges Wesen ist die Sprache, in der geschaffen wurde" (W. Benjamin, Ges. Schr. Bd. 2.1, p. 149), la forma impersonal del verbo "geschaffen" alude, de acuerdo con la versión española de R. Blatt, a la vez a la creación del hombre en el medium del lenguaje y a la creación de las cosas, y del mundo, o también la creación en un sentido genérico. 


\section{DE LA REPRODUCCIÓN TÉCNICA AL ESPECTÁCULO}

significado, el significante y el sujeto desaparece así en beneficio de una concepción creadora de la palabra como el medium universal que comparte el lenguaje de los seres humanos y de las cosas. En una bella frase resume Benjamin esta concepción metafísica, idealista y antipositivista del lenguaje como medium de una comunicación espiritual universalista: "en el nombre, la entidad espiritual de los hombres comunica a Dios a sí misma". 10

En una de las páginas más emocionantes del ensayo Sobre el lenguaje Benjamin interpreta el pasaje del Génesis que trata sobre la caída y la expulsión del Paraíso. Este es definido como estado de completa armonía entre el lenguaje de las cosas y el lenguaje humano. En el podía el nombre cumplir perfectamente su sentido creador. Pero la caída fue la escisión de aquella unidad a través de un juicio sobre lo bueno y lo malo devenido exterior a aquella fundamental relación mimética. "El saber de lo bueno y lo malo -escribe Benjamin- abandona al nombre; es un conocimiento desde afuera, la imitación no creativa de la palabra creadora." ${ }^{11}$ Esta cita es algo más que una simple visualización de su teoría lingüística. Su apelación a una relación mimética que al mismo tiempo es una relación creadora en el lenguaje encierra tanto una teoría de la experiencia cognitiva como un programa estético. Pero también recoge un momento crítico, emancipador y mesiánico: la crítica de una figura instrumental del conocimiento como juicio, la experiencia cognitiva de la mimesis como salvación, y la felicidad y la armonía del paraíso como su último despertar. Es esta precisamente la perspectiva desde la que creo que debe contemplarse el análisis de la desarticulación de la concepción aurática, cultural y ritual de la obra de arte por la obra comprendida como producción técnica, como aparato y como simulacro de la realidad en la época de la "formación" o del "modelamiento" estéticos de

\footnotetext{
${ }^{10}$ Ibid., t. 2,1, p. 144.

${ }^{11}$ Ibid., Bd. 2,1, p. 152-3.
} 
Eduardo Subirats

las masas; bajo esta perspectiva de la experiencia como mimesis la enseñanza benjaminiana sobre la obra de arte en la era de su reproductibilidad técnica logra articular una dimensión analítica con una intención crítica, una filosofía del arte con una teoría crítica de la sociedad, bajo el signo de un horizonte de salvación.

Unos años después del ensayo sobre el lenguaje, Benjamin escribió la Crítica de la violencia (1921). Las cuestiones respectivas de uno y otro ensayos, el lenguaje y la violencia, se complementan en su clara polarización. En la Crítica Benjamin desarrolla una reflexión sobre la violencia como el extremo opuesto y el límite a aquella dimensión mimética del lenguaje, de la comunicación universal de las cosas y el ser humano.

"La crítica de la violencia es la filosofía de su propia historia" ${ }^{12}$-tal es el espíritu que define el ensayo de Benjamin. En la perspectiva intelectual de esta sentencia, que pone de manifiesto la violencia como elemento fundante de las relaciones sociales de derecho, y por tanto como constitutivo de su historia, se encuentran ecos del ensayo de Georges Sorel sobre el mismo tema. Allí, en la obra del crítico francés, la violencia es la verdad que esconde la "sublimidad" de las relaciones jurídicas bajo el ropaje del progreso y de la paz social. "La férocité ancienne tend à être remplacèe par la ruse et beaucup de sociologues estiment que c'est là un progrès sérieux... tandis que nous voyon régner aujourd'hui le mensonge, la fausseté, la perfidie..." ${ }^{13}$ Benjamin asume en lo fundamental la misma tesis: la violencia interviene, incluso en los casos más favorables, en toda relación de derecho, ya sea como violencia fundadora, ya sea como violencia conservadora del derecho: "no existe igualdad -escribe en este mismo sentido. En el mejor de los casos hay violencias igualmente grandes". ${ }^{14}$

12 Ibid., p. 202.

${ }_{13}^{13}$ Geoges Sorel, Réflexions sur la violence, Paris 1919, p. 288.

${ }^{14}$ W. Benjamin, op. cit., Bd. 2,1, p. 198. 


\section{DE LA REPRODUCCIÓN TÉCNICA AL ESPECTÁCULO}

Pero el interés de este análisis de la violencia no reside solamente en la dimensión crítica subyacente al reconocimiento de relaciones de fuerza, violencia y crueldad bajo el orden del derecho, el "sublime" orden de la justicia humana, como escribía sarcásticamente Sorel. Más allá de la distinción del doble papel instrumental de la violencia fundadora o conservadora del derecho y del poder -lo que vincula históricamente su pensamiento con la tradición de filosofía del derecho de Hobbes, de Hegel y de Nietzsche-el centro de atención del planteamiento benjaminiano reside en esclarecer el nexo entre mito, violencia, derecho y destino. "Fundación del derecho equivale a fundación de poder y es, por ende, un acto de manifestación inmediata de la violencia. Justicia es el principio de toda fundación divina de fines; poder, el principio de toda fundación mítica de derecho.." ${ }^{15}$

La comparación entre la Crítica de la violencia con el ensayo Sobre el lenguaje no afecta solamente el aspecto externo de una polarización extrema entre lenguaje y mímesis como comunicación universal, y violencia como medio instrumental del derecho. El lenguaje como expresión y participación mimética en las cosas configura, en efecto, el límite más allá o más acá del cual comienza el medio y el reino de la violencia. Pero del mismo modo que existe un lenguaje como medium de una comunicación universal en la creación, así también existe un mundo de relaciones inviolentas o un mundo de violencia expresiva, inmediata. Benjamin manifiesta explícitamente que también en el orden de la interacción humana existen nexos libres de violencia, por consiguiente de comunicación y de participación: "Dondequiera que la cultura del corazón haya hecho accesibles medios limpios de acuerdo, se registra la conformidad inviolenta". ${ }^{16}$ Pero la comparación puede llegar más lejos: al lado divino a la vez del lenguaje y de la violencia. Divino era el hombre en aquel estado en que su armonía de las cosas lo delataba como principio creador: en el paraíso. Así también existe una violencia no definida como

${ }^{15}$ Walter Benjamin, De la violencia y otros ensayos, Madrid: ed. E. Subirats, 1991, p. 198.

${ }^{16}$ Ibid., p. 191. 
Eduardo Subirats

medio instrumental de la fundación o la conservación del derecho; la violencia como expresión, la violencia como ira o furia de los dioses, la violencia como manifestación de un destino.

\section{6}

El pensamiento de Benjamin describe una crisis cultural que a la postre se confunde con su concepto de modernidad. Sus signos históricos son el progreso y la ruina; sus síntomas estéticos, los cambios estructurales debidos a la naturaleza objetiva de la obra de arte y a las nuevas formas técnicamente mediadas de percepción de la realidad. En ensayos como La obra de arte en la época de su reproductibilidad técnica o El narrador esta crisis es analizada bajo una perspectiva definida: el empobrecimiento de la percepción de lo real, la suplantación de la experiencia consciente por el procesamiento inconsciente del "aparato" reproductivo, la producción técnica del sistema de la realidad o de una segunda naturaleza, consideradas como obra de arte. Quizás sean las tesis de Elnarrador las que en este sentido arrojan un cuadro más nítido. En ellas la contraposición de la narración como experiencia y el universo comunicativo de la noticia y la información arroja un negativo balance: lo maravilloso y lo lejano, es decir aquello que se corresponde a la dimensión arcaica del aura de las artes visuales, es desplazado por la noticia plausible, la reproducción exacta u objetiva, el dato susceptible de comprobación. Aquel mismo carácter de la objetividad exacta que distinguía la reproducción técnica es realizado y descrito en estas tesis sobre la narración en relación al empobrecimiento de la experiencia individual de lo real. También la dimensión temporal que habita en la experiencia narrable y narrada es eliminada en el sistema de la comunicación mediática en favor del valor inmediato e instantáneo de la noticia. El fetichismo de lo actual inherente a su valoración mercantil aparece desde esta perspectiva mediática, como el reverso de un tiempo presente vacío desde el punto de vista de la vida. Por tanto tampoco en la noticia deja huella el sujeto, aquel mismo problema, a la vez epistemológico y estético, que Benjamin desarrolló asimismo en su artículo Experiencia y pobreza. ${ }^{17}$ En fin, en el

${ }^{17}$ Cf. Walter Benjamin, Discursos internımpidos I, op. cit., p. 165-s. 


\section{DE LA REPRODUCCIÓN TÉCNICA AL ESPECTÁCULO}

mundo de la información no se constituye ya, como en el de la narración, una comunidad en el medium de la experiencia. El receptor es definido, más bien, en la soledad de su constitución técnica. ${ }^{18}$

Las tesis negativas esbozadas en los ensayos de Benjamin fueron punto de partida de uno de los aspectos más importantes de la Teoría crítica de Horkheimmer y Adorno: el análisis de la "industria cultural" o de la "Ilustración como fraude a las masas", desarrollada en el tercer capítulo de Dialektik der Aufklärung. ${ }^{19}$ Las categorías centrales que formula este ensayo, en torno a la uniformación, aislamiento y manipulación mediáticos de las masas, al empobrecimiento de la experiencia y la desarticulación del sujeto del conocimiento como individuo autónomo capaz de efectuar una experiencia de lo real recogen, entre otros, estos aspectos elementales de la crítica benjaminiana. Hoy esta perspectiva teórica sigue siendo fundamental para análisis del universo mediático, así como para toda perspectiva crítica sobre la moderna "sociedad del espectáculo". La teoría de la comunicación de Habermas debe mencionarse en este sentido más bien como una tentativa destinada, en parte, a neutralizar desde su mismo interior las dimensiones críticas de esta teoría de la experiencia.

La fundamentación metafísica de la experiencia, la teoría de la mimesis y la filosofía del lenguaje desarrollados por Benjamin en los mencionados ensayos encuentran en este contexto de la teoría crítica de la sociedad industrial su adecuado lugar. Una crítica filosófica cuyo "elemento marxista era algo así como el vuelco boca a bajo del elemento metafísico-teológico" -como escribió Gershom Scholem a propósito de Benjamin. ${ }^{20}$ Una filosofía y una metafísica que arrojan al mismo tiempo un modelo analítico de la sociedad y la cultura modernas, y una teoría de la salvación: aquella promesa mesiánica que Benjamin anunció en el Angelus Novus como la dimensión espiritual de la ruptura revolucionaria del continuum histórico.

${ }^{18} \mathrm{Cf}$. El narrador, tesis VI, VII, IX y XV, en: W. Benjamin, De violencia, op. cit.

${ }^{19}$ Max Horkheimer, Theodor W. Adorno, Dialektik der Aufklänung, Amsterdam 1947, p. 144-ss.

${ }^{20}$ Gershom Scholem, Walter Benjamin und sein Engel, en: Siegried Unseld (editor), Zur Aktaulität Walter Benjamins, Frankfur a.M., 1972, p. 87, 134-5. 